\title{
BMJ Open Patterns and predictors of mortality in a semi-urban population-based cohort in Sri Lanka: findings from the Ragama Health Study
}

Anuradhani Kasturiratne (D), ${ }^{1}$ Dileepa Senajith Ediriweera ${ }^{2}$
Shamila Thivanshi De Silva, ${ }^{3}$ Madunil Anuk Niriella, ${ }^{3}$ Uthuru Beddage Thulani, ${ }^{1}$
Arunasalam Pathmeswaran $10,{ }^{1}$ Anuradha Supun Dassanayake, ${ }^{4}$
Arjuna Priyadarsin De Silva, ${ }^{3}$ Sureka Chackrewarthy, ${ }^{5}$ Udaya Ranawaka ${ }^{3},{ }^{3}$
Norihiro Kato, ${ }^{6}$ Ananda Rajitha Wickremasinghe, ${ }^{1}$ Hithanadura Janaka de Silva ${ }^{3}$

ABSTRACT

Objective To describe patterns and predictors of mortality in a semi-urban population in Sri Lanka.

Design A prospective population-based cohort study. Setting Ragama Medical Officer of Health area in the Gampaha district, Sri Lanka.

Participants Adults between 35 and 64 years of age were recruited using an age stratified random sampling technique in 2007.

Measures At baseline, we recorded socio-demographic, lifestyle, anthropometric, biochemical and clinical data of the participants. Over 10 years, we obtained the cause and date of death from the death registration documents of deceased participants. We determined the survival probability of the cohort over 10 years and estimated Hazard ratios (HRs) for all-cause mortality (ACM), cardiovascular mortality (CVM) and cancer-related mortality (CRM) using Cox's proportional hazards model. We also estimated the survival probabilities for men and women in each 10-year age group and standardised mortality ratio relative to the source population.

Results There were 169 deaths over 10 years with standardised mortality rates of 5.3 and 2.4 per 1000 years of follow-up for men and women, respectively. Independent predictors of: ACM were older age, lower income, smoking and diabetes mellitus while gender, education, occupation, harmful alcohol use, waist circumference and hypertension were not; CVM were older age, lower income, smoking, diabetes and hypertension while gender and harmful alcohol use were not; CRM was older age while gender, smoking and diabetes were not. Those engaged in clerical and technical occupations or unemployed had a lower risk of CRM as compared with those engaged in elementary occupations. Conclusions Older age, lower income, smoking, diabetes and hypertension strongly predict mortality in this cohort. Addressing the identified modifiable predictors through behavioural modification will improve longevity in similar populations.

\section{INTRODUCTION}

Mortality is one of the strongest indicators of the health status in a population and the
Strengths and limitations of this study

- This is a population-based prospective cohort study which provides high quality epidemiological evidence on temporal associations.

- We used national vital registration data with a high coverage and completeness (99.9\%), but they may have inaccuracies in documenting the cause of death.

Loss to follow-up of the original cohort (8.7\%) is a limitation of this study.

- Relationships observed may be distorted by confounding, but multivariable analysis that have been carried out is likely to have minimised this.

easiest to measure due to it being an unambiguous endpoint. ${ }^{1}$ Due to rapid socio-economic development and improved living conditions, significant reductions in adult mortality have been observed in all regions of the world in the last three decades. In both high-income and middle-income countries the the most common cause of death is cardiovascular disease. South Asia, with a population of 1.9 billion, records over 12 million deaths annually ${ }^{2}$ and the majority of these deaths are due to cardiovascular causes which are linked to intermediate metabolic conditions such as, diabetes mellitus and hypertension. ${ }^{3}$ It has been documented that people of South Asian origin develop diabetes mellitus at a younger age and at lower levels of metabolic risk when compared with Caucasians. ${ }^{4}$ South Asians who make up a considerable proportion of the migrant population in high-income countries have also shown a higher risk of diabetes at lower metabolic risk levels. ${ }^{5}{ }^{6}$ Mortality due to cancer is estimated to be about 1.3 million deaths in South-East Asia region ${ }^{7}$ 
and accounts for about $10 \%$ of mortality in the region. ${ }^{8}$ All cause, cardiovascular and cancer mortality in Asia have shown strong links to socio-economic disadvantage. ${ }^{9}$ However, only a few studies have been conducted to describe the patterns and predictors of mortality in South Asian populations and even fewer are based on population-based cohorts. ${ }^{10}$

Well organised and functioning vital registration systems provide high quality and timely mortality data that are of great value for epidemiological purposes. At present, the rate of death registration in Sri Lanka exceeds $99 \%$ and on registration, a death certificate is issued. The death certificate includes the identification data of the deceased, the time, date, place and the medical cause of death and the designation and credentials of the officer certifying the death; it is required for the disposal of the deceased. ${ }^{11}$ Although data from the vital registration system and hospital statistics provide evidence on the importance of cardiovascular disease as the leading cause of death across South Asia, ${ }^{12} 13$ there is limited epidemiological information on the patterns and predictors of mortality from population-based studies conducted in this region. This dearth of information hampers creating the awareness it deserves for better decision-making and resource allocation for appropriate public health and preventive measures for control of behavioural and metabolic risk factors of cardiovascular disease. Results from studies conducted outside South Asia have a limited impact on attracting the attention of local decision-makers and health administrators.

To address this dearth of information and the resultant gaps in practice, we conducted an analysis to describe the patterns of all-cause mortality (ACM), cardiovascular mortality (CVM) and cancer-related mortality (CRM) and their predictors in a population-based cohort in Sri Lanka, using baseline data of the cohort and mortality data reported by the vital registration system.

\section{METHODS}

\section{Study design}

We prospectively followed-up participants of a population based cohort study over a period of 10 years to correlate their baseline characteristics and mortality outcomes.

\section{Study setting and population}

Our cohort lives in the Ragama Medical Officer of Health $(\mathrm{MOH})$ area in the Gampaha district of Sri Lanka. Gampaha district is the second most populous district of Sri Lanka with a population of approximately 2.3 million. ${ }^{14}$ Sri Lankans enjoy universal free education and free healthcare facilities at the point of delivery. Universal franchise was introduced in 1931 and all citizens above 18 years of age are included in the electoral register since $1959 .{ }^{15}$ Gampaha district with mostly rural and semi-urban characteristics, records the country's highest overall adult literacy rate of $98.5 \%$ and an overall life expectancy at birth of 73.2 years for men and 79.9 years for women. ${ }^{14}$ The district is divided into $16 \mathrm{MOH}$ areas to provide population based preventive healthcare services. ${ }^{16}$ The Ragama MOH area, which has semi-urban characteristics and a population of 81687 living in an area of $21 \mathrm{~km}^{2}$, is the smallest of these and is the field practice area of the Faculty of Medicine, University of Kelaniya. ${ }^{17}$

At the commencement of the study in 2007, 3012 adults between 35 and 64 years of age living in the Ragama $\mathrm{MOH}$ area were recruited using age stratified random sampling from the electoral register (sampling frame) conforming to the ratio of 1:2:2 from each of the three 10-year age groups (35 to 44, 45 to 54 and 55 to 64 years, respectively). ${ }^{18}$ Participant recruitment was done between July 2007 and March 2008. At the baseline assessment 2985 of the recruited participants had complete data and were followed-up as the Ragama Health Study (RHS) cohort. We included all the participants of the RHS cohort in this analysis.

\section{Data and data sources}

After providing informed written consent at recruitment, the study participants underwent baseline screening that included anthropometric, clinical and biochemical assessments and their socio-demographic, lifestyle, medical and health-related information were obtained through an interviewer-administered questionnaire developed in the local languages. Medical history provided by the participants was verified with medical records by the medically qualified research staff. The assessment covered a wide range of risk factors attributed to cardiovascular diseases including biochemical tests for assay of blood glucose and lipids, serum insulin, glycated haemoglobin and alanine transaminase levels. In 2010 and 2014, two follow-up assessments of the cohort were conducted using similar methods. In 2014, 2148 (72\%) of the 2985 original participants attended follow-up. The rest of the participants were followed-up in the community by research staff and their vital status was determined. If any participant had died, a copy of his/her death certificate was obtained and details were recorded. From July 2017 to November 2018, we conducted a population based follow-up of the RHS cohort at household level by contacting all households by telephone or by post, followed by home visits if a death was reported. The follow-up visits were conducted by trained research assistants with a medical/health sciences background, who met family members of the deceased participants to collect information on their cause of death. They obtained a copy of the death certificate to correctly ascertain the date and the cause of death. If the death certificate was not available with the family, more preliminary hospital or field death declaration documents were perused to ascertain the date and the cause of death. The vital status of 2724 (91.3\%) participants was obtained. The database was updated with the outcome data obtained during the follow-up assessment after a cleaning and verification process. At each stage of this prospective cohort study, participants who did not participate were (1) those who did not wish to be followed-up 


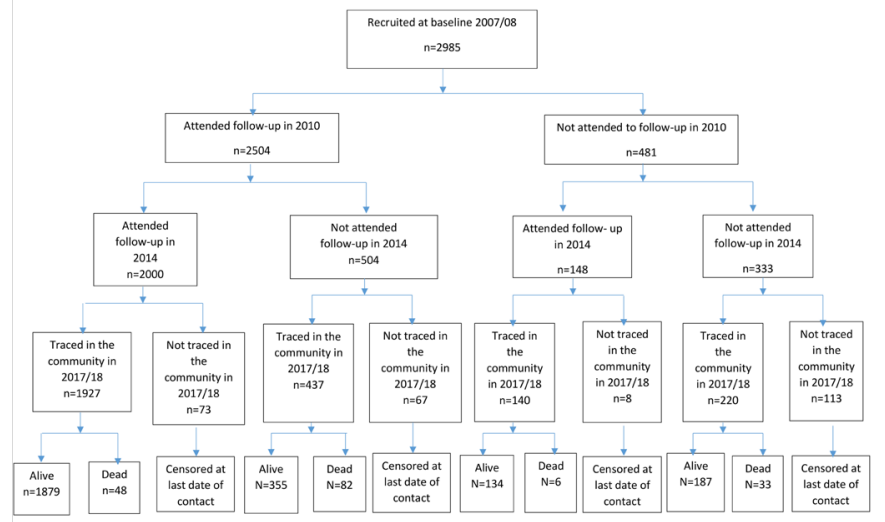

Figure 1 The flow of participants through the follow-up period.

in the study, (2) those who migrated out of the area or (3) those who migrated overseas. The flow of participants through the follow-up period and how their outcome was ascertained in given in figure 1.

\section{Data analysis}

We constructed Kaplan-Meier survival curves to determine the survival probability of the cohort after accounting for all-cause mortality, and mortality due to cardiovascular and cancer-related causes, at 10 years from recruitment. The participants who were not traceable in 2017 were censored at their last date of contact. We compared deceased persons and persons alive by important baseline characteristics. We considered sociodemographic variables defined as follows: age defined by number of completed years at recruitment, sex as the reported biological sex, low educational level as having an educational level below General Certificate of Education (G.C.E.) Ordinary Level completion, low income as belonging to the lowest income quartile of the study population and occupation based on the classification of International Labour Office. ${ }^{19}$ Smoking status was defined by reported use on an average day (current smoker/past smoker/never smoker). Harmful alcohol use was defined by Asian cut-offs for harmful alcohol consumption (14IU/week for men and $7 \mathrm{IU} /$ week for women) estimated using reported weekly consumption. Obesity was defined as a body mass index $\geq 25 \mathrm{~kg} / \mathrm{m}^{2}$. A waist circumference $\geq 90 \mathrm{~cm}$ for men and $\geq 80 \mathrm{~cm}$ for women was defined as a high waist circumference. Presence of diabetes was defined as a verifiable past history of diabetes or having a fasting blood glucose level $\geq 126 \mathrm{mg}$ / $\mathrm{dL}$ at baseline. Hypertension was defined as a verifiable past history of high blood pressure or persistent systolic blood pressure $\geq 140 \mathrm{~mm} \mathrm{Hg}$ and/or diastolic blood pressure $\geq 90 \mathrm{~mm} \mathrm{Hg}$ at baseline. Dyslipidaemia was defined as a verifiable past history of dyslipidaemia or having a total cholesterol level $\geq 240 \mathrm{mg} / \mathrm{dL}$ or a low-density lipoprotein cholesterol level $\geq 160 \mathrm{mg} / \mathrm{dL}$ or a serum triglyceride level $\geq 150 \mathrm{mg} / \mathrm{dL}$ or a high-density lipoprotein (HDL) cholesterol level below sex specific cut-offs for HDL $(\leq 40 \mathrm{mg}$ / $\mathrm{dL}$ for men and $\leq 50 \mathrm{mg} / \mathrm{dL}$ for women) at baseline.

Survival analysis was done using right censored data. Follow-up time was defined as the time between 2007 to death, or the date at which the patient was last confirmed to be alive (censoring time). Comparison of survival rates due to ACM, CVM and CRM by age-sex strata within ACM, CVM and CRM were conducted using Kaplan-Meier survival function curves. Cox's proportional hazards (CPH) models were used to identify independent risk factors of mortality due to ACM, CVM and CRM. Initially the probable risk factors were screened with simple CPH models and the risk factors with a $\mathrm{p}<0.2$ were considered for constructing multivariable $\mathrm{CPH}$ models for ACM, CVM and CRM. Effects of risk factors on mortality are presented as HRs and their 95\% CIs.

We standardised the observed mortality rates using the method of indirect standardisation for the district and the country and constructed life tables for the cohort.

\section{Missing data}

Among variables collected at baseline, the percentage of missing data was small. We censored our outcome variables, ACM, CVM and CRM at the last date of contact with the research staff, if they could not be traced in the community or if they were already lost to follow-up. We did not perform sensitivity analyses. We have indicated the numbers available for each variable in table 1 . We have also compared the baseline socio-demographic characteristics of the participants who were and were not traced in online supplemental table 1.

\section{Potential sources of bias}

We have attempted to address potential sources of bias using a set of strategies in the design of this study. The participants were sampled using stratified random sampling allowing for representative sampling from the reference population within the specific age strata to address selection bias. Information bias was minimised through the use of standard interviewer-administered questionnaires for data collection and regular in-service training of data collectors who were from a medical or health sciences background. Certain data collected from participants have been verified with documented information, for example, medical history. Outcome data have been obtained from official documents minimising information bias. We have also attempted to minimise confounding through use of multivariable models to determine predictors of mortality.

\section{Patient and public involvement}

The study was designed in 2007. At the design stage, participants were not consulted on development of research questions or outcome measures. However, noncommunicable diseases, especially cardiovascular disease, diabetes and hypertension were recognised as important public health problems by the public and the study 
Table 1 Baseline characteristics of the RHS cohort

\begin{tabular}{|c|c|c|c|c|c|}
\hline Characteristic* & Total & Alive & $\begin{array}{l}\text { Deceased } \\
\text { from all } \\
\text { causes }\end{array}$ & $\begin{array}{l}\text { Deceased from } \\
\text { cardio-vascular } \\
\text { causes }\end{array}$ & $\begin{array}{l}\text { Deceased from } \\
\text { cancer-related } \\
\text { causes }\end{array}$ \\
\hline Mean age $(S D)$ years $(n=2985)$ & $52.4(7.8)$ & $52.2(7.8)$ & $56.9(6.0)$ & $57.4(5.4)$ & $57.5(5.2)$ \\
\hline Age group: 35-44 years & $514(17.2)$ & $509(18.1)$ & $5(3.0)$ & $1(1.4)$ & $0(0.0)$ \\
\hline $45-54$ years & $1140(38.2)$ & $1092(38.8)$ & $48(28.4)$ & $19(26.0)$ & $9(29.0)$ \\
\hline $55-64$ years & $1331(44.6)$ & $1215(43.1)$ & $116(68.6)$ & $53(72.6)$ & $22(71.0)$ \\
\hline \multicolumn{6}{|l|}{ Education $(\mathrm{n}=2971)$} \\
\hline Below G.C.E. Ordinary Level & $1358(45.7)$ & $1263(45.1)$ & $95(56.2)$ & 35 (47.9) & $16(51.6)$ \\
\hline \multicolumn{6}{|l|}{ Occupation (n=2964) } \\
\hline Administrative and professional & $285(9.6)$ & $273(9.8)$ & $12(7.1)$ & $5(6.9)$ & $2(6.4)$ \\
\hline \multicolumn{6}{|l|}{ Monthly family income $(n=2921)$} \\
\hline Lowest income quartile & $426(14.6)$ & $385(14.0)$ & $41(25.0)$ & $17(23.9)$ & $8(26.7)$ \\
\hline \multicolumn{6}{|l|}{ Smoking $(n=2985)$} \\
\hline Non-smokers & $2131(71.4)$ & $2045(72.6)$ & $86(50.9)$ & $39(53.4)$ & $16(51.6)$ \\
\hline Ex-smokers & $368(12.3)$ & $323(11.5)$ & $45(26.6)$ & $20(27.4)$ & 7 (22.6) \\
\hline Current smokers & $486(16.3)$ & $448(15.9)$ & $38(22.5)$ & $14(19.2)$ & $8(25.8)$ \\
\hline \multicolumn{6}{|l|}{ Alcohol $(n=2985)$} \\
\hline Harmful alcohol users & $554(18.6)$ & 505 (17.9) & $49(29.0)$ & $21(28.8)$ & $9(29.0)$ \\
\hline \multicolumn{6}{|l|}{ Overweight and obese $(n=2974)$} \\
\hline Dyslipidaemia (n=2969) & 1909 (64.3) & $1802(64.3)$ & $107(63.7)$ & $50(68.5)$ & $17(56.7)$ \\
\hline
\end{tabular}

${ }^{*}$ Presented as number (percentage) unless specified otherwise.

BMI, body mass index; G.C.E., General Certificate of Education; RHS, Ragama Health Study.

addressed a well-recognised gap in knowledge. The public was involved in participant recruitment and follow-up in this study. Community volunteers provided support to the research team to access selected participants throughout the recruitment phase. In the follow-up phase, the death registration documents available with the family members of the participants was the main source of outcome information. They were retrieved with the co-operation of the family members. The results of this analysis will be disseminated to the study participants and their families through the RHS clinic and information leaflets delivered to their homes via post.

\section{RESULTS}

At recruitment, the mean age of our cohort was 52.4 $(\mathrm{SD}=7.8)$ years with $1349 / 2985(45.2 \%)$ men. Respectively
$17.2,38.2 \%$ and $44.6 \%$ of the sample were distributed in the three 10-year age groups 35 to 45 years, 45 to 54 years and 55 to 64 years. Overall, $45.5 \%$ had received an education below G.C.E. Ordinary Level and $14.3 \%$ were in the lowest income quartile. Selected baseline sociodemographic, lifestyle, anthropometric and clinical characteristics of the participants are presented in relation to their vital status in table 1. During the period 2007 to 2018, 169 (107 men) participants had died giving an overall crude mortality rate of $7.9 \%$ for men and $3.8 \%$ for women. Standardised mortality rates were 5.3 and 2.4 per 1000 years of follow-up for men and women, respectively. Survival probability of the cohort overall and in relation to cardiovascular and cancer-related causes are shown in figure 2. Overall survival of the cohort at 10 years was $95.1 \%$ (94.3 to 95.9 ). Survival probabilities of men and 


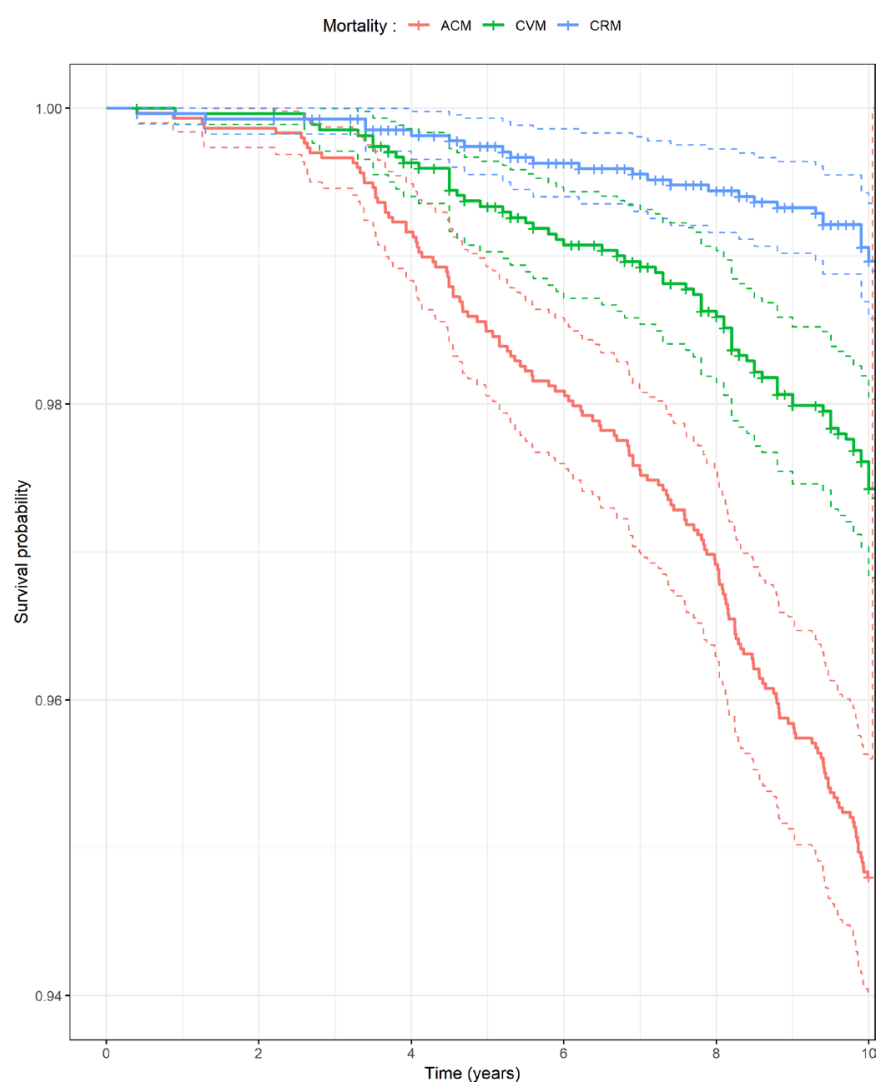

Figure 2 Survival probability of the cohort overall and in relation to cardiovascular and cancer-related causes. ACM, all-cause mortality; CRM, cancer-related mortality; CVM, cardiovascular mortality.

women in baseline age groups 35 to 44,45 to 54 and 55 to 64 years for ACM, CVM and CRM are presented in figure 3 .

HRs of selected individual variables for ACM, CVM and CRM are presented in table 2. Older adults (45 to 54 years $\mathrm{HR}=4.35$ (95\% CI: 1.73 to 10.92$)$ ), (55 to 64 years, $\mathrm{HR}=9.21 \quad(95 \%$ CI: 3.76 to 22.5$)$, men $(\mathrm{HR}=2.15 \quad(95 \%$ CI: 1.58 to 2.95$)$ ), those with a lower educational level (HR=1.55 (95\% CI: 1.15 to 2.11)) and a lower income (HR=1.95 (95\% CI: 1.37 to 2.78)), smokers (ex-smokers HR=3.20 (95\% CI: 2.23 to 4.60)) and (current smokers HR=1.97 (95\% CI: 1.34 to 2.88)), harmful alcohol users ( $\mathrm{HR}=1.80$ (95\% CI: 1.29 to 2.51$)$ ), those with diabetes $(\mathrm{HR}=3.03$ (95\% CI: 2.24 to 4.11$)$ ) and hypertension $(\mathrm{HR}=1.69$ (95\% CI: 1.25 to 2.30$)$ ) had a significantly higher risk of ACM. The unemployed (HR=0.54 (95\% CI: 0.32 to 0.88$)$ ), professionals or administrators $(\mathrm{HR}=0.44$ (95\% CI: 0.21 to 0.91$)$ ) and those with a higher waist circumference (HR=0.72 (95\% CI: 0.53 to 0.98$)$ ) had a significantly lower risk of ACM. Older adults (45 to 54 years $\mathrm{HR}=8.61(95 \%$ CI: 1.15 to 64.28$))$, (55 to 64 years HR=20.80 (95\% CI: 2.88 to 150.45$))$, males $(\mathrm{HR}=2.12$ (95\% CI: 1.32 to 3.41$)$ ), those with a lower income (HR=1.86 (95\% CI: 1.08 to 3.22)), ex-smokers $(\mathrm{HR}=3.20$ (95\% CI: 1.86 to 5.50$)$ ), harmful alcohol users $(\mathrm{HR}=1.81$ (95\% CI: 1.09 to 3.01)), those with diabetes (HR=3.95 (95\% CI: 2.48 to 6.27$)$ ) and hypertension (HR=2.61 (95\%

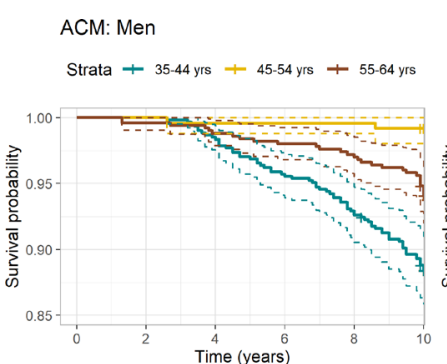

ACM: Women

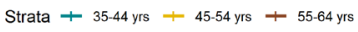

CVM: Men

Strata $+35-44$ yrs $+45-54$ yrs $+55-64$ yrs

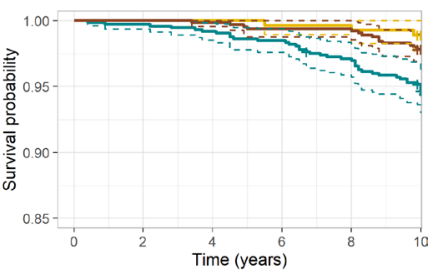

CVM: Women
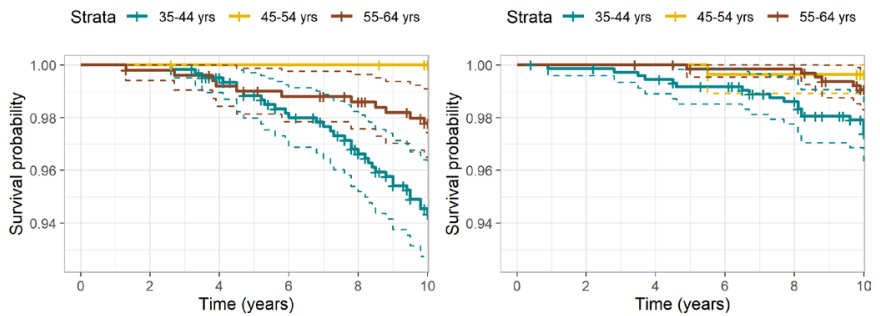

CRM: Men

CRM: Women

Strata $+35-44$ yrs $+45-54$ yrs $+55-64$ yrs
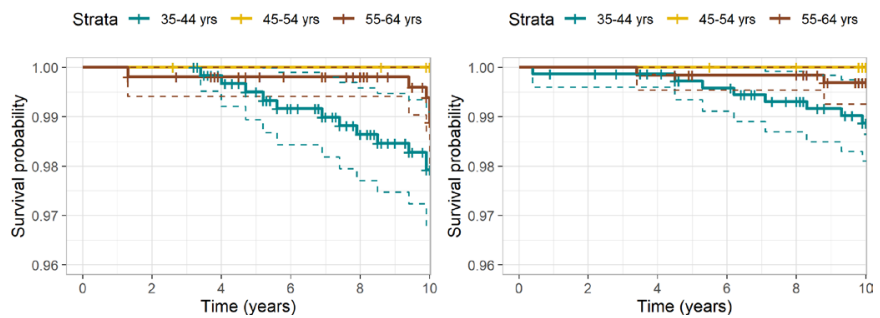

Figure 3 Survival probabilities of men and women in baseline age groups. ACM, all-cause mortality; CRM, cancerrelated mortality; CVM, cardiovascular mortality.

CI: 1.60 to 4.26$)$ ) had a significantly higher risk of CVM. Older adults ( 55 to 64 years HR=3.14 (95\% CI: 1.45 to $6.83)$ ), ex-smokers (HR=2.64 (95\% CI: 1.09 to 6.42)) and those with diabetes (HR=2.41 (95\% CI: 1.18 to 4.92$)$ ) had a significantly higher risk of CRM. The unemployed $(\mathrm{HR}=0.27$ (95\% CI: 0.10 to 0.68$))$ and clerical and technical workers $(\mathrm{HR}=0.29$ (95\% CI: 0.09 to 0.91$))$ had a significantly lower risk of ACM.

Results of multiple variable analysis performed to determine independent predictors of mortality are presented in table 3. The risk of ACM increased in those between 45 and 54 years of age by 3.42 (95\% CI: 1.35 to 8.63 ) and in those between 55 and 64 years of age by 5.99 (95\% CI: 2.42 to 14.83) as compared with those between 35 and 44 years of age; in those in the lowest income quartile by 1.91 (95\% CI: 1.33 to 2.75 ) as compared with those with a higher income; in a past smoker by 2.95 (95\% CI: 2.02 to 4.32 ) and a current smoker by 2.60 (95\% CI: 1.75 to 3.87 ) as compared with a non-smoker; and in those with diabetes at baseline by 2.86 (95\% CI: 2.08 to 3.93) as compared with non-diabetics. The risk of CVM increased in those between 55 and 64 years of age by $10.10(95 \%$ CI: 1.37 to 74.61 ) as compared with those between 35 and 44 years of age; in those in the lowest income quartile by 1.83 (95\% CI: 1.04 to 3.21 ) as compared with those with a higher income; in a past smoker by 2.77 (95\% CI: 1.55 to 4.97 ) and a current smoker by 2.31 (95\% CI: 1.21 to 4.41$)$ as compared with a non-smoker; in those with diabetes 
Table 2 HRs of individual level baseline characteristics for all cause, cardiovascular and cancer-related morality

$$
\mathrm{HR}^{*}(95 \% \mathrm{Cl})
$$

\begin{tabular}{|c|c|c|c|}
\hline Characteristic & All-cause mortality & Cardiovascular mortality & Cancer-related mortality \\
\hline Age & 1.09 (1.07 to 1.12$)$ & $1.11(1.07$ to 1.15$)$ & 1.11 (1.05 to 0.18$)$ \\
\hline $\begin{array}{l}\text { Age group } \\
35-44 \text { years }\end{array}$ & Reference level & Reference level & Reference level \\
\hline $45-54$ years & 4.35 (1.73 to 10.92$)$ & 8.61 (1.15 to 64.28$)$ & Reference level \\
\hline $55-64$ years & 9.21 (3.76 to 22.5$)$ & 20.80 (2.88 to 150.45$)$ & 3.14 (1.45 to 6.83$)$ \\
\hline \multicolumn{4}{|l|}{ Gender } \\
\hline Females & Reference level & Reference level & Reference level \\
\hline Males & 2.15 (1.58 to 2.95$)$ & 2.12 (1.32 to 3.41$)$ & 1.99 (0.97 to 4.10$)$ \\
\hline \multicolumn{4}{|l|}{ Education } \\
\hline Above G.C.E. Ordinary Level & Reference level & Reference level & Reference level \\
\hline Below G.C.E. Ordinary Level & 1.55 (1.15 to 2.11$)$ & 1.13 (0.71 to 1.80$)$ & 1.27 (0.63 to 2.57$)$ \\
\hline \multicolumn{4}{|l|}{ Occupation } \\
\hline Elementary occupations & Reference level & Reference level & Reference level \\
\hline Administrative and professional & 0.44 (0.21 to 0.91$)$ & 0.54 (0.17 to 1.78$)$ & $0.22(0.04$ to 1.10$)$ \\
\hline Clerical and technical & 0.61 (0.34 to 1.06$)$ & 0.84 (0.33 to 2.13$)$ & $0.29(0.09$ to 0.91$)$ \\
\hline Unemployed & 0.54 (0.32 to 0.88$)$ & 0.70 (0.30 to 1.65$)$ & 0.27 (0.10 to 0.68$)$ \\
\hline \multicolumn{4}{|l|}{ Monthly family income } \\
\hline Upper income quartiles & Reference level & Reference level & Reference level \\
\hline Lowest income quartile & 1.95 (1.37 to 2.78$)$ & 1.86 (1.08 to 3.22$)$ & 2.08 (0.93 to 4.69$)$ \\
\hline \multicolumn{4}{|l|}{ Smoking } \\
\hline Non-smoker & Reference level & Reference level & Reference level \\
\hline Ex-smoker & $3.20(2.23$ to 4.60$)$ & 3.20 (1.86 to 5.50$)$ & 2.64 (1.09 to 6.42$)$ \\
\hline Current smoker & 1.97 (1.34 to 2.88$)$ & 1.62 (0.88 to 2.99$)$ & 2.19 (0.94 to 5.12$)$ \\
\hline \multicolumn{4}{|l|}{ Alcohol } \\
\hline Non-harmful alcohol user & Reference level & Reference level & Reference level \\
\hline Harmful alcohol user & 1.80 (1.29 to 2.51$)$ & 1.81 (1.09 to 3.01$)$ & 1.76 (0.81 to 3.83$)$ \\
\hline \multicolumn{4}{|l|}{ BMI } \\
\hline $\mathrm{BMl}<25 \mathrm{~kg} / \mathrm{m}^{2}$ & Reference level & Reference level & Reference level \\
\hline $\mathrm{BMI} \geq 25 \mathrm{~kg} / \mathrm{m}^{2}$ & $0.81(0.59$ to 1.11$)$ & 0.98 (0.61 to 1.58$)$ & $1.10(0.54$ to 2.25$)$ \\
\hline \multicolumn{4}{|l|}{ Waist circumference } \\
\hline Males $\leq 90 \mathrm{~cm}$, Females $\leq 80 \mathrm{~cm}$ & Reference level & Reference level & Reference level \\
\hline Males $>90 \mathrm{~cm}$, Females $>80 \mathrm{~cm}$ & 0.72 (0.53 to 0.98$)$ & 0.84 (0.53 to 1.34 ) & 0.88 (0.43 to 1.78$)$ \\
\hline Diabetes & $3.03(2.24$ to 4.11$)$ & $3.95(2.48$ to 6.27$)$ & 2.41 (1.18 to 4.92$)$ \\
\hline Hypertension & 1.69 (1.25 to 2.30$)$ & 2.61 (1.60 to 4.26 ) & $1.80(0.88$ to 3.67$)$ \\
\hline Dyslipidaemia & 0.97 (0.71 to 1.33$)$ & 1.19 (0.73 to 1.96$)$ & $0.73(0.35$ to 1.50$)$ \\
\hline
\end{tabular}

Bold statistics indicate significant variables - that is, 1 is not included in the $95 \% \mathrm{Cl}$.

*The age groups 35 to 44 years, 45 to 54 years and 55 to 64 years have been sampled in 1:2:2 ratio

BMI, body mass index; G.C.E., General Certificate of Education.

at baseline by 3.30 (95\% CI: 2.07 to 5.58 ) and those with hypertension at baseline by 1.90 (95\% CI: 1.12 to 3.25$)$ as compared with those without. The risk of CRM increased in those between 55 and 64 years of age by $3.19(95 \%$ CI: 1.44 to 7.05 ) as compared with those between 35 and 54 years of age. Those in clerical and technical occupations (HR=0.31 (95\% CI: 0.10 to 0.96$)$ ) and those who are unemployed (HR=0.21 (95\% CI: 0.08 to 0.55$)$ ) had a lower risk of CRM as compared with those in elementary occupations. Indirect standardisation of observed mortality rates for men and women showed that mortality in this cohort was about $50 \%$ lower compared with the district and national populations (table 4).

Comparison of basic socio-demographic characteristics of the RHS cohort who were traced and not traced in $2017 / 2018$ for outcome ascertainment is presented in 
Table 3 Risk factors of all-cause, cardiovascular and cancer mortality from multiple variable analysis

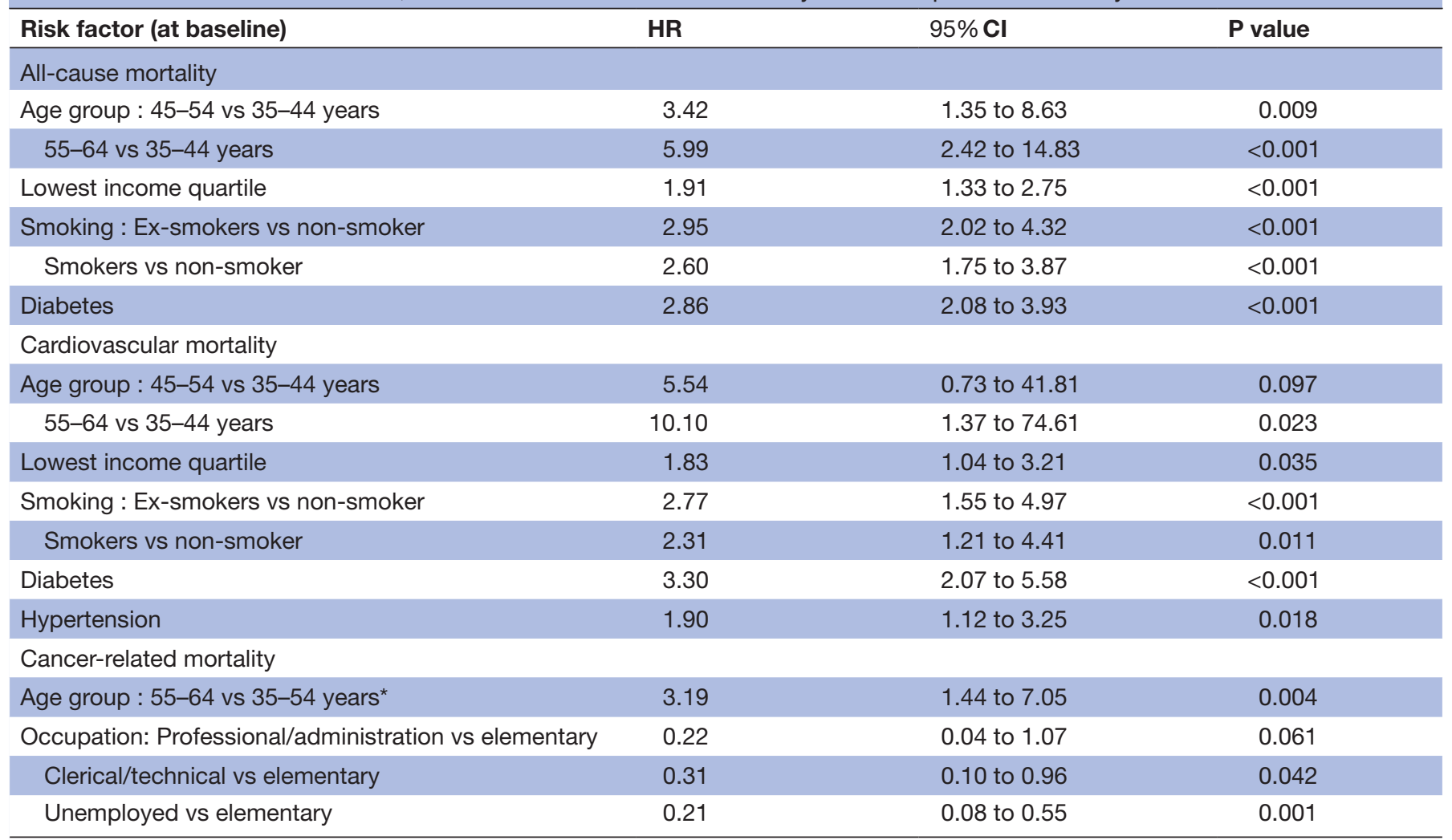

*There were no cancer-related deaths in 35 to 44 age group. Therefore, age groups 35 to 44 and 45 to 54 were merged together.

online supplemental table 1. Life tables constructed for the RHS cohort are presented in online supplemental table 2.

\section{DISCUSSION}

We have demonstrated the patterns and predictors of ACM, CVM and CRM in a cohort of semi-urban adults living in Sri Lanka, using baseline data of a prospective population-based cohort study and mortality data from the national vital registration system. Our cohort comprised middle-aged adults with a mean age of 52.4 $(\mathrm{SD}=7.8)$ years at baseline and $45 \%$ men. The overall survival probability of the cohort was $95.1 \%$ at 10 years after recruitment. ACM was associated with older age groups, low income, both current and previous smoking and diabetes at baseline. CVM was associated with older age groups, low income, both current and previous smoking, diabetes and hypertension at baseline. CRM was associated with older age and those engaged in clerical and technical occupations and those who are unemployed had a lower risk of CRM as compared with those in elementary occupations.

Older age is the main risk factor for mortality globally. ${ }^{20}$ We found that low income was associated with both ACM and CVM, while CRM was associated with elementary occupations. The association between poverty and mortality is well documented. ${ }^{21} 22$ Diabetes was also associated with both ACM and CVM. Diabetes has been identified as the third leading contributor for deaths in Sri Lanka, behind ischaemic heart disease and stroke. ${ }^{23}$ Similar to documented findings, ${ }^{24-26}$ both current and past smoking was associated with ACM. Hypertension at baseline was associated with CVM, similar to findings from a number of cohorts across settings in both highincome and middle-income regions. ${ }^{12}{ }^{20}$ Our findings highlight the importance of well-known non-modifiable predictors of mortality, such as, older age, while at the same time demonstrating that well-recognised modifiable risk factors of mortality like low income, elementary occupations, current and past smoking, diabetes and hypertension are associated with ACM and CVM in this population.

Standardisation of the mortality data of our cohort for the district showed that our population is healthier than the general population. The RHS cohort population lives in the catchment area of the Colombo North Teaching Hospital which is the second largest tertiary care hospital in the country in terms of bed strength and healthcare facilities. The area also has two large private hospitals and many general practice clinics. In addition, the population has exclusive access to long-term and continuing health facilities in the RHS clinic at the Faculty of Medicine, University of Kelaniya, since the formation of the cohort to-date. This service has offered routine follow-up care, health advice and a continuous supply of medication to all participants who have metabolic conditions 
Table 4 Indirect standardisation of mortality for men and women

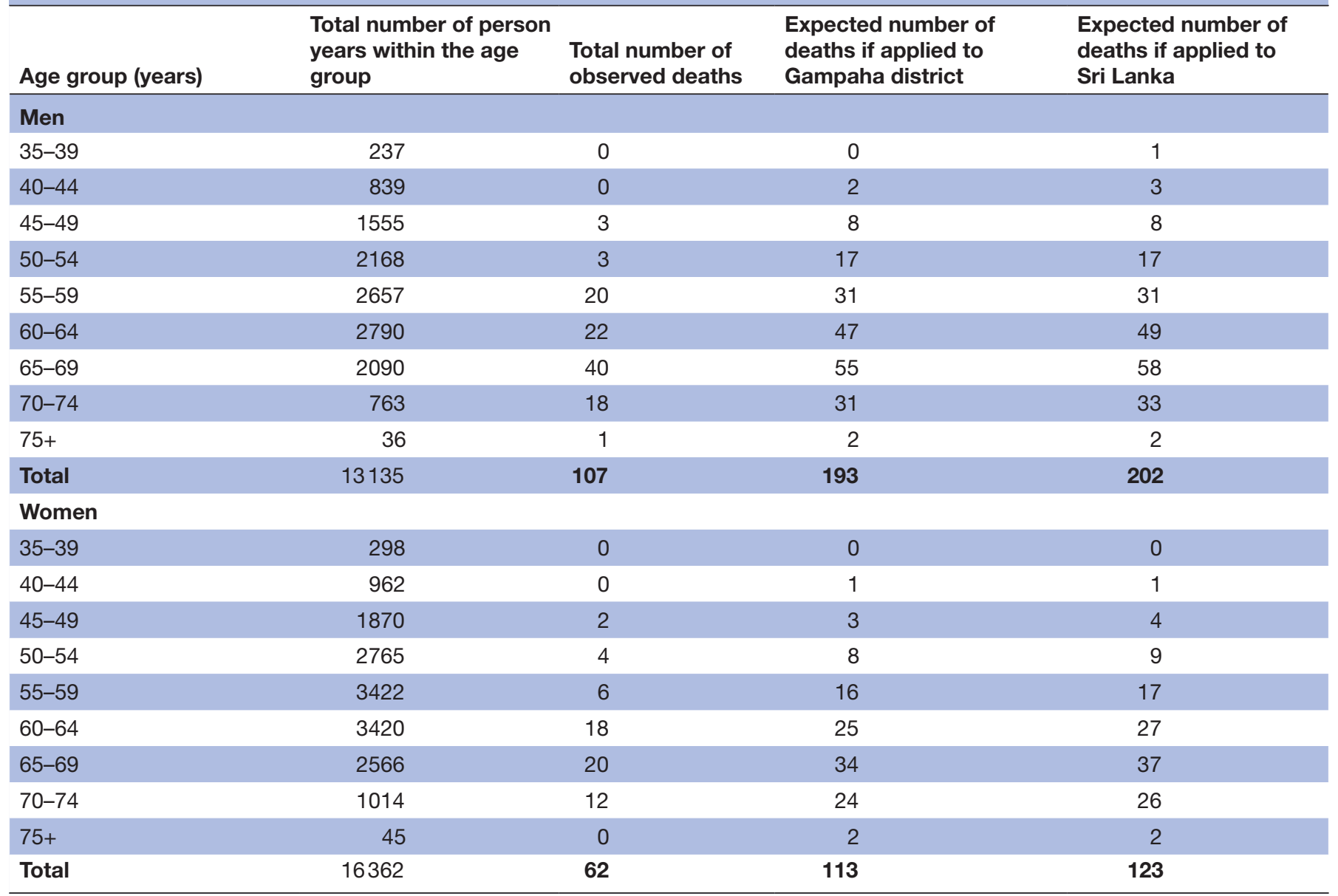

like diabetes and hypertension with referral links to specialised care based on requirement. Volunteer bias in participation in screening and research programmes and intensified health services available to the participants of this cohort could be responsible for their apparent better health status.

Our cohort of 2985 participants is a relatively small cohort from South Asia. However, our comprehensive baseline data and stringent follow-up mechanisms, together with a reliable vital registration system strengthen the relevance of our findings and their applicability for the country and the region. Population based cohort studies provide the most robust methodology for determining the temporal association between a risk factor and its outcome in a population. ${ }^{27}$ We have taken steps to address the effect of confounding on these relationships through multiple variable analysis. Sri Lanka's vital registration system has been in operation for over 100 years. ${ }^{28}$ Transformations in knowledge and technology over the last two to three decades have led to improvement in documentation of vital events and the use of modern information technology for collecting, storage and retrieval of vital statistics. ${ }^{11}$ It is a legal requirement for all births and deaths to be registered in the vital registration system. ${ }^{28}$ Furthermore, availability of the death certificate issued by the Registrar General's Department is mandatory for death benefits and property settlements, and are retained by the next-of-kin of the deceased and the local public administration system. ${ }^{29}$ In the absence of complete and up-todate health information systems covering risk levels and outcome information, the methods we have employed, which are straightforward and simple enough to be easily replicated by other researchers with similar data sources, can be used to determine the patterns and predictors of mortality in any low-income and middle-income setting with a reasonable vital registration system.

The predictors of mortality reported in this study are well known. However, this is the first time this has been reported for this setting. The added benefits of reporting these results are (1) it can increase the emphasis on preventing identified modifiable risks, (2) allocation of limited health resources can be planned to target these conditions and (3) increase the attention of policymakers to prevent premature mortality.

\section{Limitations}

The relatively small size of the cohort and the modest number of mortality outcomes reported over the first 10 years of follow-up is our main limitation. Due to the small number of outcomes we were compelled to categorise mortality into three main groups as ACM, CVM and CRM. We expect to follow-up this cohort long-term and examine 
the mortality trends over the next 10 years to address this limitation. Despite improvements in recording cause of death in mortality statistics, deficiencies can exist in the death registration process that can reduce the accuracy of documenting the cause of death. Validating the documented cause of death in official documents was beyond the scope of this study and we acknowledge this as a potential limitation.

Sri Lanka being a small country with access to free education and healthcare has minimal country-wide variation. Given the diversity of the study area in the Gampaha district, we believe that the risk factor prevalences and associations reported in different subpopulations in this study will be the same for generalising the findings of the study both in Sri Lanka and the South Asian region.

\section{Recommendations}

Low income is known to be associated with increased ACM across high-income, middle-income and low-income countries and even where health systems are tax funded and provided free at the point of delivery. ${ }^{22}{ }^{30}$ Many underlying mechanisms that link poverty with poorer health outcomes like socio-economic barriers for access to healthy behaviours, and the resulting choice of unhealthy alternatives, exist at population level. ${ }^{31}{ }^{32}$ Universal measures to improve living standards by addressing poverty can create manifold benefits including the promotion of healthy behaviours that can reduce the incidence and improve the control of intermediate metabolic risk factors of common mortality outcomes, and thus improve longevity. Along with this, preventive health services should increase their emphasis on behavioural modification for healthy lifestyles at population level to address tobacco control, and prevention and control of diabetes and hypertension.

\section{Author affiliations}

${ }^{1}$ Department of Public Health, University of Kelaniya Faculty of Medicine, Ragama, Sri Lanka

${ }^{2}$ Centre for Health Informatics, Biostatistics and Epidemiology, University of Kelaniya Faculty of Medicine, Ragama, Sri Lanka

${ }^{3}$ Department of Medicine, University of Kelaniya Faculty of Medicine, Ragama, Sri Lanka

${ }^{4}$ Department of Pharmacology, University of Kelaniya Faculty of Medicine, Ragama,

Sri Lanka

${ }^{5}$ Department of Biochemistry and Clinical Chemistry, University of Kelaniya Faculty of Medicine, Ragama, Sri Lanka

${ }^{6}$ Department of Gene Diagnostics and Therapeutics, National Center for Global Health and Medicine Research Institute, Shinjuku-ku, Tokyo, Japan

Contributors AK, NK, ARW and HJdS conceptualised and designed the study. STDS, MAN, ASD, APDS, SC and UR managed the study implementation and data collection. AP, DSE and UBT managed the database and conducted the data analysis. AK and HJdS drafted the manuscript. All authors contributed to improving and approval of the final version of the manuscript.

Funding This work was supported by grants from the National Center for Global Health and Medicine (17K1); KAKENHI (Grant-in-Aid for Scientific Research (B) \#20406019) from the Ministry of Education, Culture, Sports, Science and Technology of Japan; Japan International Co-operation Agency through the project on Health Promotion and Preventive Care Measures of Chronic Non-communicable Diseases (NPP) implemented by the Ministry of Health, Sri Lanka (project \#0701475); Strengthening Research Grant from the Ministry of Higher Education, Sri Lanka.
Competing interests None declared.

Patient and public involvement Patients and/or the public were involved in the design, or conduct, or reporting, or dissemination plans of this research. Refer to the Methods section for further details.

Patient consent for publication Not required.

Ethics approval Ethical clearance was obtained from the Ethics Review Committee, Faculty of Medicine, University of Kelaniya, for both baseline and follow-up assessments of the Ragama Health Study and principles of ethical research were upheld in all encounters with the participants.

Provenance and peer review Not commissioned; externally peer reviewed.

Data availability statement Data are available upon reasonable request. Deidentified participant data will be available upon reasonable request as decided by the data management committee of the RHS. Please contact the corresponding author (Anuradhani Kasturiratne,0RCID ID 0000-0001-5260-2394).

Open access This is an open access article distributed in accordance with the Creative Commons Attribution Non Commercial (CC BY-NC 4.0) license, which permits others to distribute, remix, adapt, build upon this work non-commercially, and license their derivative works on different terms, provided the original work is properly cited, appropriate credit is given, any changes made indicated, and the use is non-commercial. See: http://creativecommons.org/licenses/by-nc/4.0/.

ORCID iDs

Anuradhani Kasturiratne http://orcid.org/0000-0001-5260-2394

Arunasalam Pathmeswaran http://orcid.org/0000-0003-4065-2639

Udaya Ranawaka http://orcid.org/0000-0002-4050-062X

\section{REFERENCES}

1 Bonneux L. How to measure the burden of mortality? J Epidemiol Community Health 2002;56:128-31.

2 United Nations, Department of Economic and Social Affairs PD. World mortality 2017 data booklet, 2017. Available: https://www. un.org/en/development/desa/population/publications/pdf/mortality/ World-Mortality-2017-Data-Booklet.pdf

3 GBD 2017 Causes of Death Collaborators. Global, regional, and national age-sex-specific mortality for 282 causes of death in 195 countries and territories, 1980-2017: a systematic analysis for the global burden of disease study 2017. Lancet 2018:392:1736-88.

4 Unnikrishnan R, Gupta PK, Mohan V. Diabetes in South Asians: phenotype, clinical presentation, and natural history. Curr Diab Rep 2018;18:30.

5 Lee JR, Yeh H-C. Trends in the prevalence of type 2 diabetes and its association with mortality rates in Asians vs. whites: results from the United States National health interview survey from 2000 to 2014. J Diabetes Complications 2018;32:539-44.

6 Banerjee AT, Shah BR. Differences in prevalence of diabetes among immigrants to Canada from South Asian countries. Diabet Med 2018;35:937-43.

7 Cancer IA for Ron. WHO south-east Asia region, 2018. Available: https://gco.iarc.fr/today/data/factsheets/populations/995-whosouth-east-asia-region-searo-fact-sheets.pdf [Accessed 14 Jun 2020].

8 World Health Organization. Global health estimates, 2016.

9 Vathesatogkit P, Batty GD, Woodward M. Socioeconomic disadvantage and disease-specific mortality in Asia: systematic review with meta-analysis of population-based cohort studies. $J$ Epidemiol Community Health 2014;68:375-83.

10 Anjana RM, Unnikrishnan R, Mugilan P, et al. Causes and predictors of mortality in Asian Indians with and without diabetes-10 year follow-up of the Chennai Urban Rural Epidemiology Study (CURES 150). PLoS One 2018;13:e0197376.

11 Registrar General's Department SL. Death registration, 2019. Available: http://www.rgd.gov.lk/web/index.php/en/ [Accessed 5 Nov 2019].

12 Coates MM, Kamanda M, Kintu A, et al. A comparison of allcause and cause-specific mortality by household socioeconomic status across seven indepth network health and demographic surveillance systems in sub-Saharan Africa. Glob Health Action 2019;12:1608013-12.

13 Foreman KJ, Marquez N, Dolgert A, et al. Forecasting life expectancy, years of life lost, and all-cause and cause-specific mortality for 250 causes of death: reference and alternative scenarios for 2016-40 for 195 countries and territories. Lancet 2018;392:2052-90. 
14 Department of Census and Statistics Sri Lanka. Census of population and housing 2012 Sri Lanka, 2015. Available: http:// www.statistics.gov.lk/PopHouSat/CPH2011/index.php?fileName= Activities/TentativelistofPublications [Accessed 1 Nov 2019].

15 Election Commission of Sri Lanka. Universal franchise and elections, 2019. Available: https://elections.gov.lk/web/en/about-us/what-wedo/universal-franchise-and-election/

16 Ministry of Health SL. Annual health statistics, 2017. Available: http:// www.moh.gov.sa/en/Ministry/Statistics/book/Pages/default.aspx

17 Ministry of Health N and IM. Mid year population estimates for medical officer of health $(\mathrm{MOH})$ areas 2018. Colombo, 2018.

18 Dassanayake AS, Kasturiratne A, Rajindrajith S, et al. Prevalence and risk factors for non-alcoholic fatty liver disease among adults in an urban Sri Lankan population. $J$ Gastroenterol Hepatol 2009;24:1284-8.

19 Office IL. International standard classification of occupations: ISCO08, 2012.

20 Preis SR, Hwang S-J, Coady S, et al. Trends in all-cause and cardiovascular disease mortality among women and men with and without diabetes mellitus in the Framingham heart study, 1950 to 2005. Circulation 2009;119:1728-35.

21 Lynch JW, Smith GD, Kaplan GA, et al. Income inequality and mortality: importance to health of individual income, psychosocial environment, or material conditions. BMJ 2000;320:1200-4.

22 Kinge JM, Modalsli JH, Øverland S, et al. Association of household income with life expectancy and cause-specific mortality in Norway, 2005-2015. JAMA 2019;321:1916-25.

23 Institute of Health Metrics and Evaluation. GBD 2017, 2019. Available: https://vizhub.healthdata.org/gbd-compare/ [Accessed 5 Nov 2019].
24 Nakamura K, Huxley R, Ansary-Moghaddam A, et al. The hazards and benefits associated with smoking and smoking cessation in Asia: a meta-analysis of prospective studies. Tob Control 2009;18:345-53.

25 Duong M, Rangarajan S, Zhang X, et al. Effects of bidi smoking on all-cause mortality and cardiorespiratory outcomes in men from South Asia: an observational community-based substudy of the prospective urban rural epidemiology study (pure). Lancet Glob Health 2017;5:e168-76.

26 GBD 2015 Tobacco Collaborators. Smoking prevalence and attributable disease burden in 195 countries and territories, 1990 2015: a systematic analysis from the global burden of disease study 2015. Lancet 2017;389:1885-906.

27 Grimes DA, Schulz KF. Cohort studies: marching towards outcomes. Lancet 2002;359:341-5.

28 Rampatige R, Gamage S, Peiris S, et al. Assessing the reliability of causes of death reported by the vital registration system in Sri Lanka: medical records review in Colombo. Health Inf Manag 2013;42:20-8.

29 Democratic Socialist Republic of Sri Lanka. Births and deaths registration act Amendment. Sri Jayawardenepura Kotte: Parliment of Sri Lanka, 2005

30 Shin WY, Kim HC, Lee T, et al. Combined effects of diabetes and low household income on mortality: a 12-year follow-up study of 505677 Korean adults. Diabet Med 2018;35:1345-54.

31 Miller V, Yusuf S, Chow CK, et al. Availability, affordability, and consumption of fruits and vegetables in 18 countries across income levels: findings from the prospective urban rural epidemiology (pure) study. Lancet Glob Health 2016;4:e695-703.

32 Mayén A-L, Marques-Vidal P, Paccaud F, et al. Socioeconomic determinants of dietary patterns in low- and middle-income countries: a systematic review. Am J Clin Nutr 2014;100:1520-31. 